How I nearly became a Marlboro Man

You think your girlfriend has given up smoking, then you find a pack of Alpine in her sock drawer. It's much the same with cigarette companies. You're sure the government has made them stub out their final ad campaign and then you discover they're sneaking out to the stairwell for a quickie on the sly.

Philip Morris is the world's largest cigarette company. They roll up and crank out Marlboro, Alpine, and Peter Jackson. Philip Morris have something hidden in their sock drawer. How do I know? Because they rang me up and tried to get me on board for a "secret" project. They wanted me to be a Marlboro Man, so to speak.

Their phone call to me was the third encounter I've had with Philip Morris over the last few years. They were obviously unaware of the first two.

The first time "Phil" and I bumped into each other was, of all places, deepest darkest Africa, where I was filming for ABC TV's Race Around The World. I was staying in this tiny village in the Ivory Coast where people lived in mud huts and sacrificed chickens. One morning, into this National Geographic scenery drove a sparkling new, freshly painted Marlboro four wheel drive. When I tried to film Marlboro's push into the Third World, the fat driver leaped out of the vehicle, got all surly, and told me to turn off the frigging camera.

The next time we met I was shooting a piece for the ABC on how Kraft (of cheese sticks fame) was actually owned by Philip Morris (of death sticks fame). A cameraman and I turned up to Kraft headquarters in Port Melbourne. We strolled in and tried to present the marketing manager with some Kraft/Philip Morris "cross promotion" ideas, like Kraft Rollies (Kraft Singles that you could roll up like cigarette papers). Next thing I knew, Kraft lawyers had contacted the ABC threatening legal action.

However, Kraft is a separate branch of Philip Morris, in a different building with different staff. And in a classic case of the left nicotine stained hand not knowing what the right one is doing, their tobacca chewin' cousins were now on the phone trying to sign me up for a project.

I'm no prohibitionist. If I was king I'd let Philip Morris hand out cigarettes at school bus stops. But their hypocrisy really irked me. I loathed the way Philip Morris sanctimoniously evoked freedom of speech to support their right to promote, yet at the first opportunity delivered legal letters to the $\mathrm{ABC}$ to shut me up. They have a track record of saluting the flag of "inalienable rights" with teary eyes while practising no such noble behaviour themselves. In the US, they've sponsored a tour of the country's Bill of Rights and commissioned a book, American voices: prize winning essays on freedom of speech, censorship and advertising bans, to build a link between the right to free speech and the right to give people lung cancer. Yet the same company started legal action against an anti-alcohol campaigner who printed up "Killer Time" t shirts, which mocked Philip Morris's 'Miller Time' beer slogan. If they're not ramming a ciggie down your throat, they're ramming a gag.

I wanted revenge on Philip Morris. And what better way than by telling them I'm interested in their secret project, finding out all the details, and then getting them printed up somewhere.

So what was this project about? I asked the Philip Morris man at the other end of the phone. He said he couldn't tell me many details until I signed the confidentiality agreement. All he could say was he wanted me to front a video show called The Buzz Team. They had already filmed one episode and they wanted me for the second. He said the money was great and I wouldn't even have to get my hands (or lungs) dirty as there was nothing that identified the show with Philip Morris or cigarettes. I asked him why any company would bother spending money on a project that didn't promote their product. He mumbled a shoulder shrug.

A couple of days later the first episode of The Buzz Team arrived in the post and I popped it in the video. It was a 30 minute hotch potch of alternative culture. A bit like Philip Morris, if Marilyn Manson was chairman. There were surreal short films, the comedian Greg Fleet reporting on the cost of body parts around the globe, a segment on getting tattoos and neo-beatniks reciting spoken word. It was clearly aimed at young people, yet as much as I had my cynic antennas strapped on and switched to high, I couldn't find a single ciggie reference in sight. Why was Philip Morris doing this? A coffee shop meeting was arranged with the Philip Morris man.

I was to meet the Buzz Team director. He was a surfie looking guy with a suntan and hair like bed springs. Within one second of the rendezvous, the confidentiality agreement was pushed in my face like so much passive smoke: "When you accept employment you accept obligation not to disclose any of this confidential or trade secret information . . . The accidental disclosure of confidential information or trade secrets can be as harmful as intentional disclosure. The safest practice is to simply avoid any discussion of confidential information with anyone ... Take particular care when talking business in public places where you can be easily overheard." 
I said I had to show it to a lawyer and left. The jig was up. I knew Philip Morris were serious when it came to legal action. I resigned myself to never finding out about the inner workings of the cigarette giant.

God hates cigs. He must, because a month later I coincidently bumped into a disgruntled former Philip Morris employee at a party. And he was willing to talk. My very own "Deep Throat". Although considering the nature of the product I think I'll call him "Sore Throat".

Did he have to sign the confidentiality agreement? "Yep."

Did he care? Sore Throat shrugged his shoulders.

So, the Buzz Team. What did it all mean? Did the buzz refer to the electronic voice box smokers stick to the hole in their throats? $\mathrm{He}$ told me it was a project developed for the Peter Jackson brand. "You'll see the colour scheme on the video cover is the same as the colour scheme on a pack of PJs."

Yes, a PJ pack is dominated by blue with a hint of red and yellow and, yes, the Buzz Team video had the same colours in roughly the same proportions. Nevertheless, this was a big mental stretch as I was studying the video, forensic style, for that type of thing and I didn't make the connection. Lucky for Philip Morris. Because, as well as overt logos, the Tobacco Advertising Prohibition Act forbids "designs that are closely associated with a tobacco product", such as the Marlboro red triangle design or the Peter Jackson colour scheme.

Everyone loves a freebie, so who gets sent this video? According to Sore Throat, the video was part of a marketing plan for the cigarette company to build up a database of young people. He told me: "Women called 'Buzz Girls' go into nightclubs with these questionnaires. And they're mostly funny questions like 'What's your favourite tool?' so it's light hearted and doesn't seem like 'Hi we're from Philip Morris and we want to know about your demographic'. I think 'what brand do you smoke?' is the final question. They tell the person the Buzz Team is just a club. But by the nature of the questions you can tell it has something to do with smoking. I reckon your average punter could work out that it was a cigarette thing. The Buzz Girls then ask, 'Can we send you out a video pack?" "

So Philip Morris had found a loophole in the Tobacco Advertising Prohibition Act. Good on them. It shows initiative.

Maybe the punter gets the Buzz Team video and makes a mental connection that it was sent by the girl who was talking about cigarettes. Or maybe the questionnaire is just market research. I rang the Buzz Team hotline, where you can purchase Buzz branded merchandise, and pretended I didn't know why I was sent the tape.

"Were you a bit out of it at a nightclub?" the girl on the other end of the phone asked.

"I guess so."

"Yeah, we get a lot of people who ring, saying they were drunk and don't remember doing a survey," she giggled empathically.
"Who's behind the Buzz Team anyway?" I asked.

Now she sounded nervous. "Um ... it's for a celebrity who wants to find out the interests of 18 to 25 year olds."

"A celebrity?" "Um . . no . . . just a company," she stuttered. She wouldn't tell me which one.

The real stroke of loophole genius is the nightclub girls. While the Tobacco Prohibition Act covers all sorts of electronic media and was no doubt penned with an eye on future technology, it seems to have overlooked what would happen if cigarette companies went back to primitive human interaction. A person on a billboard is an ad, but can a person in real life be one? I was in the Espy Hotel in St Kilda about a month ago and three models dressed as groovy 1960s airline hostesses were walking around with packs of Peter Stuyvesant (not a Philip Morris brand) displayed in transparent handbag pouches. The girls' cartoonish hairstyles and retro clothes were clearly chosen with as much an eye on brand values and target market as any magazine ad.

They were done up as airline hostesses because Peter Stuyvesant is your "international passport to smoking pleasure". The Stuyvos in their transparent handbag pouches were the logo. If these three models were on a billboard, it would be illegal. In real life they're above board, $3 \mathrm{D}$, and more interactive than any Web site.

It seems "Philip" and "Peter" want to deny that infiltrating the real world with real people is a new and major tobacco company strategy to sneak past advertising restrictions. But their cousin, Rothmans, already squealed about their practice of the same tactics in Croatia to the cigarette industry journal Tobacco Reporter. The Buzz Team project seems to follow a new lateral strategy pursued by Philip Morris.

Another covert project, uncovered earlier this year by the anti-smoking group $\mathrm{ASH}$, was a health education kit which Philip Morris produced and sent out to Australian schools (without any Philip Morris identification). Simon Chapman, the director of ASH, claimed the aim of the project was to provide a school health kit that excluded a demonisation of tobacco (which a government sponsored kit would include), as well as providing Philip Morris with a project that legitimises researching teenagers - the implication being that Philip Morris could use the results of this research to help them market their less healthy pursuits.

People like to think that tobacco companies are great dying dinosaurs-well they can't do magazine ads anymore can they?-but the Buzz Team shows otherwise. The Marlboro four wheel drive in Africa shows otherwise. Philip Morris's recent admission-after decades of denials - that smoking causes cancer, shows otherwise, too.

Why wouldn't Philip Morris get the hint from all the bans and just throw in the towel? You think giving up smoking is tough? Try giving up making more than 10 billion dollars a year in profit. With the onslaught of advertising restrictions Philip Morris seem to be following 
a simple strategy - as one door closes, try the cat flap. This article was published in The Eye (Australia) 21 October 1999.

Disclaimer: While I'm happy for this article to appear in an anti-tobacco journal I should point out that it reflects my interest in modern marketing and the censoring powers of corporations and shouldn't be taken, by association, as expressing a viewpoint about any other aspects of the tobacco/anti-tobacco debate.

JOHN SAFRAN

exfriend@hotmail.com

\section{Abreast of the West: German effort to distract Poles from the truth about smoking}

In its continuing effort to win a prize for "Most shameless distortion of the facts on smoking", Germany's Reemtsma has submitted another entry in Poland. This billboard ad is the first to show so much of the youthful flesh behind which tobacco executives hide. ${ }^{1}$ But like all promotions of the addictive product that kills half the people who use it, this one is much more interesting for what it does not expose than for what it does.

To those familiar with 1999 political debates in Poland, this particular "Test the West" imagery was clearly designed to ridicule efforts to ban tobacco advertising and promotion. Ironically, it was Reemtsma and other tobacco transnationals that were trying desperately to keep pernicious Western trends out of Poland-especially declining cigarette consumption and increasing marketing restrictions.

This otherwise revealing ad fails to point out that:

- the West-that is, the European Unionadopted a complete ban on cigarette advertising and promotion in 1998;

- on 23 April 1999 all cigarette billboard advertisements in the United States were removed, permanently, and replaced by anti-smoking ads at the expense of tobacco companies;
- scientific research has recently pointed to cigarette smoke as a cause of breast cancer ${ }^{2-4}$;

- and the link between smoking and male impotence is well established.

Unfortunately the Polish Catholic Church played into the hands of the German tobacco company by condemning the ad for its exposure of harmless flesh, rather than for glamourising a deadly product. After a few days of enormous free publicity, Reemtsma happily covered the offending breasts with the word "CENZURA", thereby even further increasing the appeal of the $\mathrm{ad}$, and further trivialising the issue of tobacco and health. Result-another victory for the "Bad Guys".

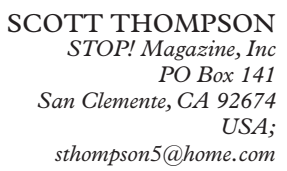

PS: This tobacco win was short lived. Five months later, in September 1999, Poland's parliamentarians voted 374-11 in favour of a complete ban on tobacco advertising and promotion.

1 http://www.wholetruth.com/asp/truth/fs_start.asp

2 Gammon MD, Hibshoosh $\mathrm{H}$, Terry $\mathrm{MB}$, et al. Cigarette smoking and other risk factors in relation to $\mathrm{p} 53$ expression in breast cancer among young women. Cancer Epidemiol Biomarkers Prev 1999;8:255-63.

3 Zheng W, Deitz AC, Campbell DR, et al. $\mathrm{N}$-acetyltransferase 1 genetic polymorphism, cigarette smoking, well-done meat intake, and breast cancer risk. Cancer Epidemiol Biomarkers Prev 1999;8:233-9.

4 Ishibe N, Hankinson SE, Colditz GA, et al. Cigarette smoking, cytochrome P450 $1 \mathrm{~A} 1$ polymorphisms, and breast ing, cytochrome P450 1A polymorphisms, and breast 58:667-71.

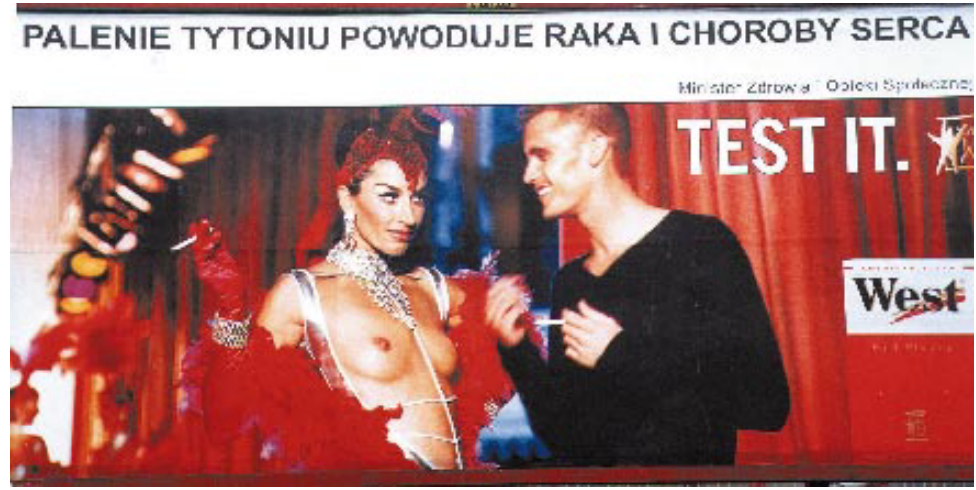

Billboard in Warsaw, April 1999. Translation of Polish: "Tobacco smoking causes cancer and heart disease" Minister of Health and Social Welfare. 